\title{
Novel Techniques for Saving Energy Consumption in Air Conditioning Systems
}

\author{
Amal El Berry \\ Department of Mechanical Engineering, National Research Centre, \\ Egypt \\ amalelberry@med.sci.eg
}

\begin{abstract}
Electrical energy consumption in air conditioning systems (ACS) is a sizeable portion of global electrical energy consumption. This means that it has a considerable share of global warming, which needs to be reduced. This article reviews the causes of excessive ACS energy consumption as well as modern trends in management and control of ACS energy consumption. Energy demand and consumption are high for air conditioning, especially in humid and hot weather. Opportunities for saving energy in cooling and heating systems depend mainly on reducing loads. Reducing the thermal loads can be achieved through new techniques Brief informational review of some of the most used ACS specifies cooling and heating loads and new techniques to reduce its energy consumption. Performance of ACSs for various types is mostly identified as the ratio of the active or beneficial output to the requisite total input of the equipment. The target to decrease the energy consumption of electrical systems is an essential step to define the components and equipment that are used to build the system and select the types that are considered as an energy saver. After ending this essential step we can concentrate on selecting and improving the overall system performance. Hence, this article provides review information of the most ACSs and specify its new techniques of energy consumption reduction.
\end{abstract}

Keywords: Energy, Saving, Consumption, Management and air conditioning.

\section{Introduction}

Different ACSs are designed to achieve suitable system functionality, each structure is unique in its operation and design. For residential and nonresidential buildings, both types have several usage, functional, requirements, occupancy design, and criteria. In addition; for the same type, there are several factors affecting the energy consumption of air-conditioning systems. The next section will cover heating and cooling energy consumption processes for residential and none residential buildings, including:

- Detailed energy consumption reasons.

- Heat balance methods as it is the basis for cooling and heating loads calculation.

- Detailed load calculations including design basics for most ACSs including all parts (fans, diffusers,ductwork, air handlers, boilers, chillers, compressors, size of piping, coils, and any other part of the system that affect indoor environment condition).

- Effect of cooling and heating load calculations on the cost of building structure and energy consumption.

- New techniques for the reduction of energy consumption.

\section{Some Causes of Energy Consumption}

\subsection{Outdoor Climate Conditions}

Fundamentals to determine summer and winter design data for greatest longitude and latitude lines. Climates data usually have power with the computer program.

- Temperature of Outdoor

- Geographical Locations (Latitude and longitude lines)

- Climate data (daily range, dry bulb, and wet bulb temperatures,)

- Wind speed and direction

In a study by Nan Wang et al. [1], the authors modeled a data center; in South Africa, to assess the energy consumption of ACSs at various temperature set points. The measured data were separated into 2 parts "training data and test data". The "Coefficient of Variation of the Root Mean Square Error" (CVRMSE) between the training and training data results is 9.7\%, 
while between the assessed data and test data is $11.5 \%$. The model has proven the only infiltration of air in latent load calculation, and the thermal storage of the building envelope such as window frames or walls is neglected. Y. Jiang et al. [2] presented a new viewpoint and means to evaluate air condoning system in buildings. High cooling temperature and the low heating temperature are realized by temperature difference reduction in heat transfer and energy transportation procedure, which will raise the energy efficiency of air condoning heating and ventilation system. It is also useful to use more renewable energy sources to provide a comfortable and healthy indoor climate.

Solar radiation incident on a building envelope is relatively mirrored and partially absorbed by surfaces. Using simulation, Chwieduk created novel basics of thermal energy usage in residential buildings for various room locations and structure of envelope parts; over 12 months [3]. For a hypothetical apartment, which has four rooms, one of each room, the heating energy requests are equal to $49.6 \mathrm{~kW} \mathrm{~h} /\left(\mathrm{m}^{2}\right.$ year). D. Kolokotsa et al. [4] have specified the influence of solar radiation taking into consideration the building location; in a city, countryside or suburbs. Usually, the ambient air is less transparent in the city, mostly due to dust and pollutants. However, the ambient air temperature in the countryside is lower than the ambient air temperature in the city. Shading is also very significant. "Task/ ambient air conditioning" (TAC) system has been considered by Ning Mao et al. [5] stating its energy consumption. A mathematical model of TAC was evaluated in 5 various weather zones. A mathematical model based on "response surface methodology" (RSM) was used to forecast the operating power of TAC built on computational fluid dynamics CFD. Results showed that considering various set points of average air temperature in the occupied zone $\left(\mathrm{t}_{\mathrm{oz}}\right)$, it was found that when $\mathrm{t}_{\mathrm{oz}}$ increases from 24 to $25^{\circ} \mathrm{C}$, energy consumption could be reduced about $23.42 \%$ in Shanghai and $36.23 \%$ in Beijing. When the relative humidity of supply air is increased from $40 \%$ to $70 \%$, the variation in energy consumption is low, and accordingly, it could be ignored. Al-Turki and Zaki [6] considered the thermal building walls performance that is subjected to periodic ambient parameters due to the effects of building insulation layer distribution on the walls and orientation. They concluded that better performance is realized when insulation layers are placed on the outer surface of walls, facing steady periodic conditions. The same result was reached by Saleh [7] and Kossecka \& Kosny [8]. Thermal performance of buildings with external walls insulation and discontinuous ACSs was investigated by Yuan $e t$ al. [9] and Al-Sanea [10]. The external walls were an arrangement of the thermal mass layer (Wall-1outside) and an insulation layer (Wall-2 inside) of the wall construction. The relative energy conservation rate $(\varepsilon) \%$ variations and $\Delta \mathrm{Q}$ showed the difference between energy consumption between buildings insulated internally and those insulated externally, with insulation thermal resistance for both orientations $\varepsilon$ is at least equal to $18 \%$ for both south and north orientations. When the insulation layer' thermal resistance $\left(\mathrm{m}^{2} \cdot{ }^{\circ} \mathrm{C} / \mathrm{W}\right)$ is increased to $1.0 \mathrm{~m}^{2 \circ} \mathrm{C} / \mathrm{W}, \varepsilon$ reached $22 \%$ and $20 \%$ for south and north orientations, respectively. The increase of $\varepsilon$ for a south-facing room is $2 \%$ than that of the northfacing room. The time delay between outdoor and indoor peak temperatures was insignificant for the first 3 days. This allows considering heat transfer through this layer to be at steady [10,11].

\subsection{Indoor Design Conditions}

The better case components (high-efficiency systems including energy-conscious behavior) shows the ideal performance (e.g. $19.2 \mathrm{kWh} / \mathrm{m}^{2}$ per year for average intensity of operations) while the bad case components (careless behavior and low-efficiency systems) are showed the bad performance (e.g. $76.6 \mathrm{kWh} / \mathrm{m}^{2}$ per year for average operation intensity, Elharidi [12]. Natural local cooling and ventilation; under control strategy were recognized as the most important factors, that have less than $50 \%$ of the electricity request of nonresidential buildings compared to fully occupation period. Aryala and Leephakpreeda, [13] presented CFD modeling of partitions effects in an air-conditioned building on thermal comfort as well as energy consumption. CFD was used to simulate the effect of indoor air variables before/after removal of partitions or installation. Consequently, "Predicted Mean Vote" (PMV) is specified as a thermal comfort indicator, while make-up Air cooling load is calculated as well as the amount of energy consumed. It was found that energy consumption was increased by $24 \%$. Hawila et al. [14] indicated that if thermostatic-control set-points were adjusted at $19{ }^{\circ} \mathrm{C}$ and $21^{\circ} \mathrm{C}$ reduces the amount of energy consumption at the least and most amount of heating energy, respectively. Thermal comfort-controlled the heating energy consumption at set-point of $20{ }^{\circ} \mathrm{C}$ is permitted to reduce about $10 \%$ compared to the set-point of $21{ }^{\circ} \mathrm{C}$. However, the set-point temperature in the thermal comfort-control is affected by 6 main factors, as shown in the next equation: 


$$
T_{a}=f\left(P M V, \bar{T}_{r}, M, T_{c l}, R H, V_{a r}\right)
$$

Where: $T_{a}=$ "air temperature, $\mathrm{k}$ ", $T_{c l}=$ "surface temperature of clothing, $\mathrm{k}$ ", $\mathrm{T}_{\mathrm{r}}=$ "mean radiant temperature, $\mathrm{k}$ ", $\mathrm{M}=$ $=$ "metabolic rate $\left(\mathrm{Wm}^{-2}\right)$ ", $\mathrm{RH}=$ "relative humidity", $\mathrm{V}_{\mathrm{ar}}=$ "air velocity"

Location of return air vent has the main effect on the system, thermal comfort, and the energy consumption reduced up to $30 \%$ in the case using ceiling exhaust air vent based on Haghshenaskashani and Sajadi, [15].

\subsection{Building Characteristics}

The ACSs chosen are affected by the building characteristics such as types and thicknesses of construction materials and insulating materials of roof, external walls, internal walls, partitions, ceiling, windows, doors, colors of roof and external wall, building size and its orientation, location, fenestrations, External/Internal shading and occupation. Marino et al. [16] investigated the optimal size of window surface that allows minimal overall energy consumption and the effect of weather conditions, insulation features of the façade or luminaries variations on optimum power consumption. Their results showed that the optimum value of window to wall ratio $\left(\mathrm{WWR}_{\mathrm{opt}}\right)$ is slightly affected by weather conditions. To consider the characteristics of nonresidential building energy consumption, statistics showed that average annual energy consumption of office buildings, hospitals, and schools are $\cong 180.98,206.92$ and $118.54 \mathrm{kWh} / \mathrm{m}^{2}$, respectively while the average annual carbon emissions are 89, 102.46 and $55.04 \mathrm{~kg} / \mathrm{m}^{2}$, respectively; Anderson [17]. ACSs have three typical variations, variable refrigerant volume system (VRV), variable air volume all-air system (VAV) and constant air volume all-air system (CAV). The three variants were analyzed by $\mathrm{H}$. Ma et al. [18] buildings $\mathrm{C}$ and $\mathrm{D}$ by building energy simulation software (eQUEST). VRV system showed a potential to save energy up to $2,389.70 \times 10^{3} \mathrm{kWh}$ annually when compared to a CAV system, with a saving percentage of $39.24 \%$. The study demonstrated the ACS' effect on the energy consumption of buildings, and that proper choice of ACS, such as VRV system, would substantially reduce the building's power consumption.

\section{Residential Cooling and Heating Load Calculations}

Characteristics variations in the residencies can lead to the difficulty to calculate the load. Time-varying heat flows combine to give a time-varying load. Heating and cooling processes are the same; a common analysis process must apply to either. With a simple method, the heating problem is reduced to a basic (Partitions to unconditioned space) UA $\Delta t$ calculation. A cooling load calculation as an example will be considered in brief dials as follow in ASHRAE standards 2017 [19].

Total sensible cooling load calculation has been estimated from heat gain due to produce by ventilation and infiltration. Sensible heat gain is the directly added heat to space, resulting in space temperatures increase. The parameters affecting a sensible cooling load:

- Heat gain due to solar (floors over crawl space exterior walls, glazing, and roof skylights)

- Infiltration and Ventilation due to building cracks, windows, and doors,

- Occupation (People, appliances and equipment)

- Lights

The complete construction could be investigated in one region of choice. The reminder also that (cooling load factor) $\mathrm{CF}$ can be observed as $\mathrm{CF}=U \times \mathrm{CLTD}$, the construction used in previous housing and nonresidential techniques. First, the values do not depend on wall orientation. This has minimal effect on total load because residences typically have a mix of exposures based on ASHRAE standards 2017 [19].

Latent heat does not effect on temperature rise, but it creates a load on the cooling equipment. Latent heat sources are appliances or machinery that evaporates water, occupation, housekeeping, and air infiltration. Residential load Factor method (RLF) calculation has two steps. The first step is calculating the cooling load factor (CFs) and heating load factor (HFs), based on all component types of the project. CFs and HFs factors are then applied to individual components by single multiplication. CFs and HFs can be pre-calculated for a specific location and representative constructions and used repeatedly. Finally, a PC spreadsheet application would employ these equations to calculate CF and HF values as well as a complete implementation of the RLF method according to ASHRAE standards 2017 [19]. 


\section{Techniques for the Reduction of Energy Consumption in ACS}

Proper choice of thermal insulation could reduce heating and cooling loads. This should reduce energy consumption, improve the building economy as well as reducing greenhouse gas emissions. Reducing operational energy is the main concern of architects designing green buildings.

\subsection{Building insulation}

One of the significant problems was realizing the classical scheduling environs in which energy and performance investigation of buildings typically were performed after an architectural design has been completed and structure has been formed by Zhu.[20]. Then Building Material Modeling (BIM) allowed multi- precise data to be covered by a model, it created a prospect for sustainability processes investigation to be performed during the design method of Schueter \&Thessling [21] and Krygiel \& Nies [22]. Since conventional bungalow houses were popular in some countries due to its tropical weather. It was the house's annual operational energy consumption was calculated through Ecotect Analysis. Those buildings' components that have the most impact on energy dissipation have been investigated. Some components, such as wall, windows, door, ceiling, and floor could lead to the most energy dissipation. The alternative changes in insulation thickness of walls and roofs during building envelope retrofit were optimized based on the primary energy consumption. It is concluded that the variants of PESR (primary energy saving ratio) versus various insulation thickness of walls and roofs based on Jie et al. [23]' study. The construction material was in situ, protected concrete, and the external walls were coated brick walls. The windows were double-glazed glass with aluminum frames. Structure of vacuum insulation panels in building system has been studied in China, Boafo et al. [24]. This study described the installation method, detailing material layers as shown in the sectional view of the insulated wall. Siroky' et al. [25], were shown that the energy consumption by using weather forecasts for the considered heating system was between $15 \%$ and $28 \%$, depending on numerous parameters, primarily the insulation level and the temperature is outside. In addition, the peak power request was minimized by $50 \%$ and the thermal relaxation in the building was reserved for a greater level. Elsarrag and Imbabi , [26] Elsarrag and Alhorr [27] and Elsarrag et al.[28]. Esam Elsarrag and Yousef Alhorr [29]' studies are compared the annual cooling demand from the simplified global Sustainability Assessment System (GSAS), energy model and the complete energetic modeling. Neither model could be estimated the "thermodynamic and fluid dynamic" methods of the dynamic insulation. Liberated model issued to compute the "heat-transfer" coefficient of the isolated walls, confirmed experimentally and then together with the energy models. Relative energy investigation, the similar interior loads, interior design conditions and heating ventilation ACSs were supposed for the 5 cities with the conforming design information reserved from local design energy codes on the land-based on [31] fit the predominant engineering applied. [30] Specifies $25^{\circ} \mathrm{C}$ as the summertime interior considered temperature, but in the concern of energy consumption in many constructions was considered to $26^{\circ} \mathrm{C}$. The same conclusions have been described by Masoso \& Grobler [32] for dry and hot weather, where the "point of thermal variation" showed the exchanging of favorable thermal isolation. Knudsen effect could be employed to produce different aerogel composites by Axel Berge PJ. [33] As reinforced carpets, granulates of different fineness or as large blocks. Thermal conductivity would be lower than $25 \mathrm{~mW} /(\mathrm{m} \mathrm{K})$, which is lower than a thermal conductivity of still air. Aerogel is a gel containing liquid phase, during drying, the liquid phase evaporates and the solid structure is preserved, Fig. 3(a). Studies prepared aerogel with very small solid content and conductivities as low as $10 \mathrm{~mW} /(\mathrm{m} . \mathrm{K})$ at room temperature. Aerogel reinforced carpet has both flexibility and tensile strength. Axel Berge PJ [33] shows an aerogel carpet in Fig.3 (b).A new advanced product for thermal insulation that works in the ambient temperature range is gas-filled panels (GFPs). Jelle BP. [34] are made of multilayer baffles that are enveloped by a sealed barrier and filled up with air, or a low conductivity gas, at atmospheric pressure and thematically sealed to maintain the gas-fill. They are made of infrared reflecting (low emissivity) materials. Figure 4 shows the inside of a GFP fitted on barrier foil with baffle structure, required to suppress radiation and convection. The employment of GFPs is being argued as studies found that the thermal conductivity of prototype GFPs is somewhat higher than traditional insulation. However, there still a room for the panels' improvement as numerous low conductivity gases, such as noble gases, still under investigation to develop high-performance panels. Innovative façade systems for creating energy-efficient buildings is being investigated. The research focused on innovative materials for façade systems such as ultra-high-performance fiberreinforced concrete (UHP-FRC). The investigation included evaluation of potential energy saving of the (Department of 
Energy) DOE medium office building, taking into account good and poor operational schedules before and after replacing the conventional façade system with the UHP-FRC façade system. The results have shown that UHP-FRC façade has higher energy performance than conventional façade system if the building is being operated based on poor practices. However, if the building is being run based on good practice, the energy savings of UHP-FRC façade seems marginal. Also, results indicated that percentages of energy-saving are higher in cold climate locations. In contrast, in warm and moist climate locations, such as Miami, operation schedules demonstrated a low impact of UHP-FRC façade panels on energy performance according to Abediniangerabi et al [35].Novel aerogel foam made from concrete reinforced silica (FC-SA) was successfully synthesized using the sol-gel technique, vacuum impregnation, and rapid ethanol supercritical drying. The produced material proved to have advantages of highly porous aerogel alongside high load-bearing of foam concrete. The foam thermal insulation performance, mechanical properties, microstructure and high-temperature stability of prepared samples have been characterized and tested by Liu et al., [36]. A simulation study of Energy Plus indicated that FC-SA has good energy conservation effect for building envelope application. Results showed that in cold winter in Burlington and Chicago, FC-SA saves $90.5 \mathrm{MW} \mathrm{h}(5.09 \%)$ and $98.3 \mathrm{MW} \mathrm{h}(6.64 \%)$ of space heating energy during the whole winter, respectively.

\subsection{Control systems automation}

It is the procedure of a heating \& air conditioning by using the control system. Generally, a sensor was used to make a comparison with the real state-run like temperature with an objective state. The controller was programmable. The control unit usually had analog and numerical inputs that permitted the size of the variable (humidity temperature, or pressure) and digital and analog outputs to regulate the transportation medium "hot to cold or water to steam". This kind of configurable systems facilitates the concept of building computerization, [37]. Extra difficult heating and ventilation ACSs could be used building automation interface to allow further controller above the heat or cool. A building could be displayed the system and response to warning produced via the system from remote and local places [38]. Building Management Systems is employed for controlling and monitoring heating and ventilation ACSs. In adding, same entrance methods were able to achieve controller by the remote process of all heating and ventilation ACSs inside elements of the internet including a simple and suitable user interface [39]. There were 2 components of the exchange layout: a model of the data to be replaced, and a technique of programming the mathematical model in an automated setup. Another part was provided by an international standard, [40], which identifies the coding of a data model given in the EXPRESS modelling language [41]. Schenck and Wilson [42] provided an exhaustive description of EXPRESS. A brief conclusion was obtainable. An EXPRESS model contains connected objects. An object was a component of the model that means some item of concern in actual. Control by sensing a Proportional-Integral-Derivative (PID) and temperature a circle where all objects in the (Bayesian Adaptive Sampling) BAS model. For the determinations of this investigation, there were 2 relations between objects: attribution and inheritance. An information model is created by J. Schein [43], including the device list, point list, network topology and arrangements a process. This model permitted a determined demonstration of the BAS from system requirement through design to process and maintenance. Okan Bingol and Kubilay Tasdelen [44]' study are constructed on a web interface, a share of a smart home system that assimilates with the operator was the web interface. The operator could achieve smart home system contribution. Operators could contact all the rooms of the system of the smart home, the motion controller, temperature value in the home, gas, smoke and door controller units through the web interface. By this method, they were capable to achieve smart home technique. As ACSs was considered accountable for a large amount of energy consumption, novel research, according to Al-Qawasmi and Tlili [45] are investigated energy efficiency and economic impact of ACS using wireless sensing in. Wireless Sensor and Actuator Networks (WSAN) was employed to detect and assess different ACS techniques with the aim of comparing them with existing, on the market. ACSs. The study found that $10 \%$ of the regular energy consumption could be saved by this replacement action.

Different input streams such as weather forecast, energy prices, and occupancies built on D. Manjarres et al. [46]' study. A serious is evaluated by A. Schieweck et al [47] of existing sensor technologies, Indoor air quality and hygiene are currently considered more seriously and considered as main aspects of smart home technologies. A novel study investigated the energy saving of a proportional-integral-derivative (PID) controlled residential ACS equipped with inverter controlled compressor motor is provided by M. Hu and F. Xiao [48]. After detecting the temperature shift from the set range, the PID controller evaluates and outputs an actuating signal to control the rotational speed of the inverter compressor motor. AC then delivers 
the generated cooling capacity to the air-conditioned room, removing the heat gains caused by disturbances including internal heat gains, solar radiation and outdoor air temperature rise. The model-based demand response (DR) control of AC inverter is employed to facilitate optimal trade-offs between thermal comfort, electricity costs, and peak power reduction in dynamic electricity pricing environment. The technique includes two major steps. The first step includes collection and prediction of input variables such as the number of inhabitants, using an infrared sensor, weather forecast, outdoor temperature, and solar radiation. Finally, the formulated nonlinear optimization problem with its user-definable weightings is solved using a genetic algorithm (GA) to estimate the optimal schedule for the next day, time-proportional integral (TPI) controllers, weather compensation and load compensation seek to improve the efficiency of the heating system based on Lomas et al. [49]' study.

\section{3. Development in ACS' components}

Form [50,51]' results presented that in relations between air-side economizers reliably, energy savings, and outperform water-side economizers through the efficiency. Model results also presented that conservative humidity restrictions must be calm or removed to improve the energy benefits of air-side economizers.

Novel research introduced nanoparticle to the chillers to increase the performance. The increase of nanoparticles Titanium dioxide $\left(\mathrm{TiO}_{2}\right)$ concentration in refrigerant increased the performance of the system. This was attributed to decreasing the work done by the compressor and to the enhancement of heat transfer rate [52]. The effect of an external thin-film cotton layer on the performance of evaporative condenser was investigated by. Kabeel et al. [53]. Chen [54] investigated extra energy consumption due to over-pressurization of the lower floors. An internal fan balancing system was proposed to eliminate or reduce this excess consumption. The QUick Energy $\underline{\text { Simulation Tool (eQUEST) }}$ simulation results indicate that 5.8\%-7.0\% annual savings on the utility bill can be achieved by installing the Internal Fan Balancing System. Results of Jinzhe Nie et al. [55] are showing that compared to the traditional ventilation system, the energy performance was more efficient essentially due to high efficient air purification capacity, reduction of cooling load and raised evaporation temperature. Analyses of different thermodynamic cryogenic cycles were carried out, by Ahmad et al. [56] with the aim of achieving the most effective configuration that would provide the required cooling and power demand for a $170 \mathrm{~m}^{2}$ residential building in Libya with a minimum (Liquid Nitrogen) $\mathrm{LN}_{2}$ consumption. The research also investigated the feasibility of the process. Results showed that at current prices $\mathrm{LN}_{2}$ would be feasible to provide cooling and power demands with a saving of up to $28 \%$, compared to conventional ACSs. However, if the $\mathrm{LN}_{2}$ prices decreased to 1.3 pence per liter, the proposed technology will be saving up to $79 \%$, compared to conventional ASCs, with a recovery of $85 \%$ of the energy stored in $\mathrm{LN}_{2}$. Figure 18 shows the process of using $\mathrm{LN}_{2}$ to generate cooling, which also is evaluated by P. Azimi et al. [57].

\subsection{Ventilation and Refrigerant Techniques}

All houses requirement ventilation to confiscate stale inside air and excessive moisture and to deliver oxygen to the inhabitants. The researchers recommend mechanical ventilation systems for all houses. The quantity of ventilation requisite depends on the number of inhabitants and their life. The control of particulate air pollution in commercial and industrial buildings is a function that is typically carried out by heating ventilation and air conditioning (HVAC) systems. Demandcontrolled ventilation was regularly used for renewed air ventilation controller in commercial or public buildings to confirm satisfactory inside air quality while consuming the slightest energy based on Kusuda [58] and Elovitz[59]. In Demandcontrolled ventilation policies, carbon dioxide application was regularly handled as a direct parameter for ventilation controller since carbon dioxide was a consistent alternate for bio overflows from a residence and not a contaminant of apprehension in buildings according to ASHRAE Standard 62-1989R[60]. However, many investigations like in A. Persily[61]' study which is pointed out that the carbon dioxide-based demand-controlled ventilation controller approach cannot sufficiently reflect the ventilation request in a space in numerous states since carbon dioxide concentration delivered no evidence on the sufficiency of ventilation level qualified to the supplier of additional pollutants, which was produced by building materials. The smallest rate of fresh air could be specified individually by the real residence for altered states in ASHRAE Standard 62-1999 [62], ASHRAE Standard 62-2001[63]. The latest standard proposes that the lowest requisite for 
the outside air ventilation rate should be specified by not individual the real residence but also the occupation area, which accounts for area-related sources and people-related sources, respectively according to ASHRAE Standard 62.1-2004 [64]. The numeral of occupiers could be recognized using a steady-state technique or a dynamic technique are determined by S.W. Wanget al. [65]. Xinhua Xu et al. [66], model-based optimum ventilation controller approach was constructed on the system reply forecast using dynamic easy models for improving the interior temperature controller of critical regions to easiness the disturb of renewed air requests amongst altered regions. When used for the temperature and ventilation controller of six regions in Yuan S, Perez R. [67]' study, the based procedure was capable of controlling the temperature within the limits and provided sufficient ventilation levels based on the habitation of the zones. However, the PI controllers failed to continue region temperatures within the preferred thermal relaxation range at all times and resulted in little ventilation when the habitation was increased. Maisotsenko cycle (M-cycle) is a capable air cooling technique which can reduce the temperature of airflow until the dew point which was not possible either in direct contact techniques or former indirect evaporative methods. Figures 19(a), 19(b) (modified from Anisimov S. et al. [68]) clarifies various counter flow structures of a precooling procedure. The psychometric chart was related to Fig. 19(b) b is illustrated in Fig. 19c from Miyazaki T. et al. [69]' study. Figure 19(c) indicates the reduction of pressure drop which required to improve the M-cycle coolers. Khan and Afroz [70] are determined that depending on the thermal loads and PCM "Phase Change Materials", approximately $2-5{ }^{\circ} \mathrm{C}$ higher evaporating temperatures were observed as illustrated in Figs. (20), (21) and (22) for $5 \mathrm{~W}$ and $10 \mathrm{~W}$ loads, respectively. These higher evaporator temperatures reduce the compressor work, enhance the heat transfer of evaporator and improve COP. Elarem et al. [71] reported a new design of a PCM heat exchanger where an experimental test rig was developed to minimize energy consumption. The technical and economical deficits related to conventional air conditioning systems can be removed using liquid desiccant air conditioning (LDAC) technologies see figs. 23 and 24 according to Daou K et al. [72]' study.

\subsection{Maintenance techniques}

To develop the consistency of building abilities, it is most important to adopt the concept and eliminate the reasons producing difficulties in all lifecycle' stages such as structure forecasting, design, structure, maintenance and to estimate quantitatively the consistency model of reliability of Hajime, et al. [73]. There were 2 ways to develop the consistency of AC competence. One technique was used to HVAC' design systems with superior concern for severance and the other technique was used to appliance protective maintenance. The design mode was studied by Takakusagi. [74], the former which was required in the situation where AC function needs a great grade of consistency like telecommunication rooms and computer The time-based precautionary maintenance was mostly realistic to the non-repairable objects which had a life distribution and its investigation was proven as a repairs rule by Barrow and Proschan [75]. The condition-built precautionary maintenance, also termed forecast maintenance, was realistic to the items where disappointment occurs inadvertently according to Takakusagi [76]. For the HVAC system's consistency, occasionally breakdowns in a life epoch of durability are characterized by Weibull analysis. Such a mode made tools mean Time between failures (MTBF) augment are used by Kawasaki [77]. A simulation model was presented by Kwak et al. [78] to investigate condition-based precautionary maintenance through a stable period maintenance checkup by maintenance personnel was to identify failure occurring. Tassou and Grace [79] described the progress of an error refrigerant, diagnosis and leakage detection system simulated by artificial intelligence and real-time performance checking. Liang and Du [80] presented an economical fault diagnosis and recognition technique for ventilation and heating ACSs by merging support vector machine (SVM) and model-built method. The new technique was built on the physical model.

\subsection{Artificial intelligence techniques}

Neural network method had been used by Rajpal et al. [81] to investigate the maintainability, availability, consistency, and reliability system. The trained neural network input layer has been including eighteen neurons, one hundred neurons in the $1^{\text {st }}$ hidden layer, ten neurons in the 2 nd hidden layer and one neuron in the output layer. The suggested network had been used to consider the influence of distinct input parameters and collections of input parameters on the compound output parameter. It was established that an artificial neural network was valued for investigating and adjusting the reliability system from the standpoint of consistency, maintainability, and availability. (Artificial Intelligent) AI's contain regions such as 
(Artificial Neural Network) ANN, genetic algorithms, expert systems, and several hybrid systems, a fuzzy logic which merge two or extra methods had been used by Kalogirou SA. [82] and Mellit A, Kalogirou SA. [83]. Speed was the highest benefit of Artificial Neural Network comparison to further expert systems. Easiness and facility of modeling a multivariable difficult to resolve grim relations between the variables and could excerpt the nonlinear relations by means of training data. Processing by using training data in ANN have been overpowering the boundaries of expected methods by mining the requisite, which had not requisite any definite investigative equations. Artificial Neural Network model of Mellit A.et al. [84] could forecast the favorite output of the system using restricted training data of solar photovoltaic system' sizing and energy systems modeling which is realized by Kalogirou [85] and Kalogirou [86]. Abdul Aframa et al. [87] Concluded several approaches for modeling and performance an inclusive assessment of the artificial neural network (ANN) built model predictive control (MPC) system design was approved as a case study in which ANN models of an ACS energy consumption reducing in a residential house located in Ontario. Detect the greatest network construction built on statistical realization data of I. Zajic et al. [88], variable air volume (VAV) ACS modeling and simulation for (Frequency division duplex) FDD applications according to A. Beghi [89]. Optimization of network construction was the main mission in artificial neural networks. The network construction could be improved by varying the factors (using trial \& error technique) to realize the consequences with the greatest precision concluded by A. Kusiak, G. Xu, [90]' investigation. In HVAC molding methods of L. Ferkl, J. Siroky, [91], have established numerous techniques like white-box models of G. Huang, S. Wang\&X. Xu [92].In Katarina Grolinger et al. [93] and A. Kusiak, M. Li, Z. Zhang [94]' studies, they have discovered the significance of more data, exactly the impact of temporal data granularity on the accuracy of electrical energy consumption and peak demand prediction. Blackbox models such as in C.M.J. Yiu [95], J. Leclere et al. [96] and R. Balan et al.[97]' studies and gray-box models of S. Wu, J.-Q. Sun [98] and Daniel L.et al. [99] to model the attitude of the HVAC' systems. The white-box models necessitate the considerate of the physics system and use the producer inclusive factors for system dynamics modeling. Equilibrium between the best overview ability and great precision was providing the gray-box models which handle the physics-based white-box model as the mathematical construction and measured data to evaluate the factors of the models. As a consequence, graybox models require extra determination to improve, have good overview abilities comparison to black-box models, and establish greater precision compared to the white-box models. In modeling of Abdul A. fram et al [100], they have been studying 2 different of the long short-term memory (LSTM): 1) standard LSTM and 2) LSTM-based sequence to sequence (S2S) architecture. Both approaches were applied to a target data set of electrical energy consumption data from one residential customer. They had been used data to improve the black-box and gray-box models. One of the purposes of their study was to inspect the achievability of consuming neural networks to guess the next day load profile before the weather conditions are known. The input layer to the network comprised of times neurons to which temperature evaluations (documented every hour).Energy supply models based on artificial intelligence responding to anti-logic or common sense that can reduce machine's energy-saving effects is investigated by Hipel, McLeod, [101]. Energy consumption due to antilogic or common sense, an intelligent cooling and heating energy supply model supported by decision-making algorithm to increase both thermal comfort and annual energy consumption reduction. The model increased thermal comfort level by $2.5 \%$ for the office building and $10.2 \%$ for residential building, and reduced energy consumption by $17.4 \%$ for the office building and $25.7 \%$ for residential building, based on Ahn and Cho, [102]' study.

\section{Conclusions and Recommendation}

\section{From the above review, the following conclusions are deduced:}

Outdoor weather, indoor design conditions, and building characteristic have an impact factor on energy consumption in ACSs. Cooling load (as an example) due to sensible and latent heat is the main reason for energy consumption. The cooling and heating load can be calculated by several methods as a function in (location, weather data, occupants, infiltration, ventilation, etc.) to determine the amount and reasons for energy consumed.

There are some new technicians are reviewed to reduce energy consumption the most important as follow: -

1. Good building insulation can reduce a working load of 50\%. New materials are used as an insulation layer which has suitable thermal characteristics like Aerogel reinforced carpet and A gas-filled panels (GFPs) is a new advanced 
product for thermal insulation that working in the output temperature. Innovative materials (as insulation) for façade systems such as ultra-high-performance fiber-reinforced concrete (UHP-FRC) has higher energy performance.

2. The energy consumption reduction is about $30 \%$ to $39 \%$ for heating and cooling, respectively when using Control systems automation "PID controller evaluates, Wireless Sensor \& Actuator Networks (WSAN) and proportionalintegral (TPI) controllers.

3. Novel research determined that the nanoparticle in the chillers increase the performance, By employment of nanoparticle $\left(\mathrm{TiO}_{2}\right)$ concentration of $0.2 \mathrm{~g} / \mathrm{L}$ and $0.6 \mathrm{~g} / \mathrm{L}$, the coefficient of performance (COP) increased to $34.39 \%$ and $55.14 \%$, respectively.

4. An internal fan balancing system was proposed to eliminate or reduce this excess consumption by using eQUEST simulation results indicate that 5.8\%-7.0\% energy consumption annual savings.

5. $\mathrm{LN}_{2}$ prices decreased to 1.3 pence per liter, the proposed technology will be saving up to $79 \%$, compared to conventional ASCs, liquid nitrogen is evaporated in the cooling tank to cool a secondary fluid used for supplying the building with the required cooling.

6. In Demand-controlled ventilation policies, carbon dioxide application was regularly handled as a direct parameter for ventilation controller.

7. Maisotsenko cycle (M-cycle) is a promising air cooling technique which can reduce the temperature of airflow until the dew point.

8. The technical and economic deficits associated with conventional air conditioning systems can be eliminated using liquid desiccant air conditioning (LDAC) Technologies

9. To develop the consistency of building abilities, the most significant matters demanding instantaneous care are to conception and eliminate the reasons producing difficulties in all lifecycle' stages such as structure forecasting, design, structure, maintenance and to estimate quantitatively the consistency model of reliability.

10. Energy consumption due to anti-logic, an intelligent cooling, and heating energy supply model supported by decision-making algorithm to increase both thermal comfort and annual energy consumption reduction. The model increased thermal comfort level by $2.5 \%$ for the office building and $10.2 \%$ for residential building, and reduced energy consumption by $17.4 \%$ for the office building and $25.7 \%$ for residential building.

\section{References}

[1] N. Wang, J. Zhang, and X. Xia, "Energy consumption of air conditioners at different temperature set points," Energy and Buildings, vol. 65, pp. 412-418, Oct. 2013.

[2] Y. Jiang, X. Liu, L. Zhang, and T. Zhang, "High-Temperature Cooling and Low-Temperature Heating in Buildings of EBC Annex 59," Energy Procedia, vol. 78, pp. 2433-2438, Nov. 2015

[3] D. Chwieduk, "Impact of solar energy on the energy balance of attic rooms in high latitude countries," Applied Thermal Engineering, vol. 136, pp. 548-559, May 2018.

[4] D. Kolokotsa, M. Santamouris, A. Synnefa, and T. Karlessi, "3.19 - Passive Solar Architecture," in Comprehensive Renewable Energy, A. Sayigh, Ed. Oxford: Elsevier, pp. 637-665, 2012.

[5] Ning Mao, Jingyu Hao, Borui Cui, Yuxing Li, Mengjie Song, Yingjie Xu, Shiming Deng, "Energy performance of a bedroom task/ambient air conditioning (TAC) system applied in different climate zones of China," Energy, vol. 159, pp. 724-736, Sep. 2018.

[6] A. Al-Turki and G. M. Zaki, "Cooling load response for building walls comprising heat storing and thermally insulating layers," Energy Conversion and Management, vol. 32, no. 3, pp. 235-247, Jan. 1991.

[7] M.A.E. Saleh, "Impact of thermal insulation location on buildings in hot dry climates," Solar Wind Technol., vol. 7, pp. 393-406, 1990.

[8] E. Kossecka and J. Kosny, "Influence of insulation configuration on heating and cooling loads in a continuously used building," Energy and Buildings, vol. 34, no. 4, pp. 321-331, May 2002. 
[9] L. Yuan, Y. Kang, S. Wang, and K. Zhong, "Effects of thermal insulation characteristics on energy consumption of buildings with intermittently operated air-conditioning systems under real time-varying climate conditions," Energy and Buildings, vol. 155, pp. 559-570, Nov. 2017.

[10] S.A. Al-Sanea, "Thermal performance of building roof elements," Build. Environ., vol. 37, pp. 665-675, 2002.

[11] Y. Zhang, K. Lin, Q. Zhang, H. Di, "Ideal thermos physical properties for free-cooling (or heating) buildings with constant thermal physical property material," Energy Build., vol. 38, pp. 1164-1170, 2006.

[12] A. M. Elharidi, P. G. Tuohy, and M. A. Teamah, "The energy and indoor environmental performance of Egyptian offices: Parameter analysis and future policy," Energy and Buildings, vol. 158, pp. 431-452, Jan. 2018.

[13] P. Aryal and T. Leephakpreeda, "CFD Analysis on Thermal Comfort and Energy Consumption Effected by Partitions in Air-Conditioned Building," Energy Procedia, vol. 79, pp. 183-188, Nov. 2015.

[14] A. A.-W. Hawila, A. Merabtine, M. Chemkhi, R. Bennacer, and N. Troussier, "An analysis of the impact of PMVbased thermal comfort control during the healing period: A case study of highly glazed room," Journal of Building Engineering, vol. 20, pp. 353-366, Nov. 2018.

[15] S. Haghshenaskashani and B. Sajadi, "Evaluation of thermal comfort, IAQ and energy consumption in an impinging jet ventilation (IJV) system with/without ceiling exhaust," Journal of Building Engineering, vol. 18, pp. 142-153, Jul. 2018.

[16] C. Marino, A. Nucara, and M. Pietrafesa, "Does window-to-wall ratio have a significant effect on the energy consumption of buildings? A parametric analysis in Italian climate conditions," Journal of Building Engineering, vol. 13, pp. 169-183, Sep. 2017.

[17] B. Anderson, "Solar Energy: Fundamentals in Building Design, Total Environmental Action," Inc., Harrisville, New Hampshire, 1975.

[18] H. Ma et al., "Analysis of typical public building energy consumption in northern China," Energy and Buildings, vol. 136, pp. 139-150, Feb. 2017.

[19] ASHRAE handbook fundamentals, 2017.

[20] Zhu, "Simulation of miscible liquid-liquid interactions," ACM symposium on virtual reality software and technology, Newport Beach, CA; 2006.

[21] A. Schueter, F. Thessling, "Building information model-based energy/exergy performance assessment in early design stages," J. Autom Constr, 2008.

[22] E. Krygiel, B. Nies, Green BIM successful sustainable design with building information modeling. Indianapolis (IN): Wiley Publishing, 2008.

[23] P. Jie, F. Zhang, Z. Fang, H. Wang, and Y. Zhao, "Optimizing the insulation thickness of walls and roofs of existing buildings based on primary energy consumption, global cost and pollutant emissions," Energy, vol. 159, pp. 11321147, Sep. 2018.

[24] Boafo FE, Chen Z, Li C, Li B, Xu T, "Structure of vacuum insulation panel in building system," Energy Build., vol. 85, pp. 644-53, 2014.

[25] Jan Siroky', Frauke Oldewurtel, Jiří Cigler and Samuel Prívara, "Experimental analysis of model predictive control for an energy-efficient building heating system," Applied Energy, vol. 88, pp. 3079-3087, 2011.

[26] E. Elsarrag, M. Imbabi, "Evaluation of dynamic insulation for zone ventilation and air conditioning in the Gulf region" ASHRAE Symposium on Sustainability and Green Buildings, Kuwait, October 5, 2009.

[27] E. Elsarrag, Y. Alhorr, "Using dynamic facade for indoor air quality, thermal comfort, and energy-efficient air conditioning," U of KEJ1, vol. 2, pp. 63-66, 2011.

[28] E. Elsarrag, Y. Al-Horr, M. Imbabi, "Improving building fabric energy efficiency in hot-humid climates using dynamic insulation," Building Simulation, vol. 5, no. 2, pp. 127-134, 2012.

[29] Esam Elsarrag and Yousef Alhorr "Modelling the thermal energy demand of a Passive-House in the Gulf Region: The impact of thermal insulation," International Journal of Sustainable Built Environment, vol. 1, pp. 1-15, 2012.

[30] Design standard for energy efficiency of public buildings (GB 50189-2005). Beijing: China Architecture and Building Press, 2005. 
[31] Code for the design of heating ventilation and air-conditioning (GB 50019-2003). Beijing: China Planning Press, 2003.

[32] O. T. Masoso, L. J. Grobler, "A new and innovative look at anti-insulation behavior in building energy consumption," Energy Build, vol. 40, pp. 1889-94, 2008.

[33] P. J. Axel Berge, Literature review of high-performance thermal insulation report in building physics. Gothenburg, Sweden: Chalmers University of Technology; 2012.

[34] Jelle BP. Traditional, "state-of-the-art and future thermal building insulation materials and solutions - properties, requirements, and possibilities," Energy Build; 43:2549-63, 2011.

[35] B. Abediniangerabi, S. M. Shahandashti, B. Bell, S.-H. Chao, and A. Makhmalbaf, "Building energy performance analysis of ultra-high-performance fiber-reinforced concrete (UHP-FRC) façade systems," Energy and Buildings, vol. 174, pp. 262-275, Sep. 2018.

[36] S. Liu, K. Zhu, S. Cui, X. Shen, and G. Tan, "A novel building material with low thermal conductivity: Rapid synthesis of foam concrete reinforced silica aerogel and energy performance simulation," Energy and Buildings, vol. 177, pp. 385-393, Oct. 2018.

[37] Role on DDC Systems in Building Commissioning, CxTPL Upgrade Project, DDC System Test Procedure, Aug. 30, 2001.

[38] KMC Controls, "Understanding Building Automation and Control Systems," Retrieved 22, April 2013.

[39] "CEDIA Find: Cool Automation Integrates Smart Air Conditioners with Third-Party Control Systems," CEPro. Retrieved 16 Jun 2015.

[40] Building Automation and Control Systems (BACS)—Part 2: Hardware, ISO Std. 16 484-2, 2004.

[41] ISO, ISO 10303-21 "Industrial automation systems and integration-Product data representation and exchange": Part 21. Implementation methods: Clear text encoding of the exchange structure, 2002.

[42] D. Schenk, P. Wilson, Information Modeling: The EXPRESS Way. Oxford University Press, 1994.

[43] J. Schein "An information model for building automation systems," Automation in Construction, vol. 16, pp. 125139, 2007.

[44] Okan Bingol, Kubilay Tasdelen, "Web-based Smart Home Automation: PLC-controlled Implementation," Acta Polytechnica Hungarica, vol. 11, no. 3, pp. 51-63, 2014.

[45] A.-R. Al-Qawasmi and I. Tlili, "Energy efficiency and economic impact investigations for air-conditioners using wireless sensing and actuator networks," Energy Reports, vol. 4, pp. 478-485, Nov. 2018.

[46] D. Manjarres, A. Mera, E. Perea, A. Lejarazu, and S. Gil-Lopez, "An energy-efficient predictive control for HVAC systems applied to tertiary buildings based on|regression techniques," Energy and Buildings, vol. 152, pp. 409-417, Oct. 2017.

[47] A. Schieweck et al., "Smart homes and the control of indoor air quality," Renewable and Sustainable Energy Reviews, vol. 94, pp. 705-718, Oct. 2018.

[48] M. Hu and F. Xiao, "Price-responsive model-based optimal demand response control of inverter air conditioners using a genetic algorithm," Applied Energy, vol. 219, pp. 151-164, Jun. 2018.

[49] K. J. Lomas et al., "Do domestic heating controls save energy? A review of the evidence," Renewable and Sustainable Energy Reviews, vol. 93, pp. 52-75, Oct. 2018.

[50] Title 24 Nonresidential Compliance Manual, 2008.

[51] Arman Shehabi, Arpad Horvath, William Nazaroff, Srirupa Ganguly, Ashok Gadgil, Kim Traber and Hillary Price "Energy Implications of Economizer Use in California Data Centers," ACEEE Summer Study on Energy Efficiency in Buildings, pp. 319-330, 2008.

[52] A. K. Dhamneya, S. P. S. Rajput, and A. Singh, "Comparative performance analysis of ice plant test rig with TiO2R-134a nano refrigerant and evaporative cooled condenser," Case Studies in Thermal Engineering, vol. 11, pp. 5561, Mar. 2018. 
[53] Kabeel, A. E., M. M. Bassuoni, and M. Abdelgaied. "Experimental study of a novel integrated system of an indirect evaporative cooler with internal baffles and evaporative condenser," Energy Conversion \& Management, vol. 138, pp. 518-525, 2017.

[54] W.-J. Chen, D. E. Claridge, and M. R. Atif, "Using internal fan balancing system to avoid excessive pressurization on high rise buildings in hot and humid climates," Energy and Buildings, vol. 152, pp. 86-95, Oct. 2017.

[55] J. Nie, Z. Li, W. Hu, L. Fang, and Q. Zhang, "Theoretical modeling and experimental study of air thermal conditioning process of a heat pump assisted solid desiccant cooling system," Energy and Buildings, vol. 153, pp. 31-40, Oct. 2017.

[56] A. Ahmad, R. Al-Dadah, and S. Mahmoud, "Liquid nitrogen energy storage for air conditioning and power generation in domestic applications," Energy Conversion and Management, vol. 128, pp. 34-43, Nov. 2016.

[57] P. Azimi, D. Zhao, B. Stephens, "Estimates of HVAC filtration efficiency for fine and ultrafine particles of outdoor origin,” Atmos. Environ., vol. 98, pp. 337-346, 2014.

[58] T. Kusuda, "Control of ventilation to conserve energy while maintaining acceptable indoor air quality," ASHRAE Trans., vol. 82, no. 1, pp. 1169-1181, 1976.

[59] D. Elovitz, "Minimum outside air control methods for VAV systems," ASHRAE Trans., vol. 101, no. 2), pp. 613-618, 1995.

[60] ASHRAE. ASHRAE Standard 62-1989R, "Ventilation for Acceptable Indoor Quality," (Public Review Draft), Atlanta, 1996.

[61] A. Persily, "Ventilation, carbon dioxide and ASHRAE Standard 62- 1989," ASHRAE J., vol. 35, no. 7, pp.40-44, 1993.

[62] ASHRAE. ASHRAE Standard 62-1999. "Ventilation for Acceptable Indoor Quality," Atlanta, 1999.

[63] ASHRAE. ASHRAE Standard 62-2001. "Ventilation for Acceptable Indoor Quality," Atlanta, 2001.

[64] ASHRAE. ASHRAE Standard 62.1-2004. "Ventilation for Acceptable Indoor Quality," Atlanta, 2004.

[65] S.W. Wang, J. Burnett, H. Chong, "Experimental validation of CO2-based occupancy detection for demand-controlled ventilation," Indoor Built Environ., vol. 8, no. 6, pp. 377-391, 1999.

[66] Xinhua Xu, Shengwei Wang, Zhongwei Sun, Fu Xiaom, “A model-based optimal ventilation control strategy of multizone VAV air-conditioning systems," Applied Thermal Engineering, vol. 29, pp. 91-104, 2009.

[67] S. Yuan, R. Perez, "Multiple-zone ventilation and temperature control of a single-duct VAV system using model predictive strategy," Energy Build, vol. 38, pp. 1248e61, 2006.

[68] S. Anisimov, D. Pandelidis, J. Danielewicz, "Numerical analysis of selected evaporative exchangers with the Maisotsenko cycle," Energy Convers Manag., vol. 31, no. 88, pp. 426e41, Dec. 2014.

[69] T. Miyazaki, A. Akisawa, I. Nikai, "The cooling performance of a building integrated evaporative cooling system driven by solar energy," Energy Build 1, vol. 43, no. 9, pp. 2211e8, Sep. 2011.

[70] I. H. Khan, H. M. M. Afroz, M. Rahman, "Enhancement of higher evaporating temperature of the household refrigerator using phase change material," pp. 1-3, 2013.

[71] R. Elarem, S. Mellouli, E. Abhilash, A. Jemni, "Performance analysis of a household refrigerator integrating a PCM heat exchanger," Appl. Therm. Eng., vol. 125, pp. 1320-1333, 2017.

[72] K. Daou, R. Z. Wang, Z. Z. Xia, "Desiccant cooling air conditioning: a review," Renewable and Sustainable Energy Reviews, vol. 10, pp. 55, 2017.

[73] Makabe Hajime, et al. "Statistical analysis of reliability model," Kyoritsu Shuppan Co., Ltd., 1989.

[74] Akira Takakusagi, "Analysis of the effect of reliability improvement and economy of condition-based preventive maintenance. Analytical study on preventive maintenance of air-conditioning system part 2," Journal of Architecture Planning and Environmental Engineering, vol. 441, pp. 43-52, 1992.

[75] R. E. Barrow, F. Proschan F, Mathematical theory of reliability. New York: Wiley, 1965.

[76] Akira Takakusagi, "Analytical study on preventive maintenance of the air-conditioning system," Journal of Architecture Planning and Environmental Engineering, vol. 430, pp. 45-53, 1991.

[77] Yoshito Kawasaki. "A study on monitored preventive maintenance." Bulletin of The Japan Institution of Marine Engineering; vol.11 (1), pp.87-96, 1976. 
[78] Ro-Yeul Kwaka, Akira Takakusagib, Jang-Yeul Sohna, Shuji Fujiic and Byung-Yoon Parkd, "Development of an optimal preventive maintenance model based on the reliability assessment for air-conditioning facilities in office buildings," Building and Environment, vol. 39 pp. 1141 - 1156, 2004.

[79] S. A. Tassou and I. N. Grace, "Fault diagnosis and refrigerant leak detection in vapor compression refrigeration systems," International Journal of Refrigeration, vol. 28, pp. 680-688, 2005.

[80] J. Liang and R. Du, "Model-based Fault Detection and Diagnosis of HVAC systems using the Support Vector Machine method," International Journal of Refrigeration, vol. 30, pp. 1104-1114, 2007.

[81] P. S. Rajpal, K. S. Shishodia and G. S. Sekhon, "An artificial neural network for modeling reliability, availability, and maintainability of a repairable system," Reliability Engineering and System Safety, vol. 91, pp. 809-819, 2006.

[82] S. A. Kalogirou, "Artificial intelligence for the modeling and control of combustion processes: a review," Progress in Energy and Combustion Science, vol. 29, pp. 515-66, 2003.

[83] A. Mellit, S. A. Kalogirou, "Artificial intelligence techniques for photovoltaic applications: a review," Progress in Energy and Combustion Science, vol. 34, pp. 574-632, 2008.

[84] A. Mellit, S. A. Kalogirou, L. Hontoria, S. Shaari, "Artificial intelligence techniques for sizing photovoltaic systems: a review," Renewable and Sustainable Energy Reviews, vol. 13, pp. 406-419, 2009.

[85] S. Kalogirou, "Applications of artificial neural networks in energy systems: a review," Energy Conversion and Management, vol. 40 pp. 1073-1087, 1999.

[86] S. A. Kalogirou, "Artificial neural networks in renewable energy systems applications: a review," Renewable and Sustainable Energy Reviews, vol. 5 pp. 373-401, 2001.

[87] Abdul Afram, Farrokh Janabi-Sharifi, Alan S. Fung and Kaamran Raahemifar "Artificial neural network (ANN) based model predictive control (MPC) and optimization of HVAC systems: A state of the art review and case study of a residential HVAC system," Energy and Buildings, vol. 141, pp. 96-113, 2017.

[88] I. Zajic, T. Larkowski, M. Sumislawska, K. J. Burnham, D. Hill, "Modelling of an air handling unit: a Hammersteinbilinear model identification approach" in 21st International Conference on Systems Engineering (ICSEng), IEEE, Las Vegas, NV, USA, pp. 59-63, 2011.

[89] A. Beghi, L. Cecchinato, F. Paggiaro, M. Rampazzo, "VAV AC systems modeling and simulation for FDD applications" in International Conference on Control \& Automation (ICCA), IEEE, Santiago, Chile, pp. 800-805, 2011.

[90] A. Kusiak, G. Xu, "Modeling and optimization of HVAC systems using a dynamic neural network," Energy, vol. 42, no. 1, pp. 241-250, 2012.

[91] L. Ferkl, J. Siroky, "Ceiling radiant cooling: comparison of ARMAX and subspace identification modeling methods," Build. Environ., vol. 45, no. 1, pp. 205-212, 2010.

[92] G. Huang, S. Wang, X. Xu, "Robust model predictive control of VAV air-handling units concerning uncertainties and constraints," HVAC R Res., vol. 16, no. 1, pp. 15-33, 2010.

[93] Katarina Grolinger, Alexandra L'Heureux, Miriam A.M. Capretz, Luke Seewald, "Energy Forecasting for Event Venues: Big Data and Prediction Accuracy," Energy and Buildings, vol. 112, pp. 222-233, 2016.

[94] A. Kusiak, M. Li, Z. Zhang, "A data-driven approach for steam load prediction in buildings," Appl. Energy, vol. 87, no. 3, pp. 925-933, 2010.

[95] C. M. J. Yiu, "Statistical modeling and forecasting schemes for the air-conditioning system" (Ph.D. Thesis), Department of Building Services Engineering, The Hong Kong Polytechnic University, 2008.

[96] J. Leclere, F. Wurtz, E. Wurtz, “A low order envelope model for optimized predictive control of indoor temperature: development methodology and calibration with a numerical model", in Proc BS2013: 13th Conference of International Building Performance Simulation Association, IBPSA, Chambery, France, pp. 2341-2348, 2013.

[97] R. Balan, J. Cooper, K.-M. Chao, S. Stan, R. Donca, "Parameter identification and model-based predictive control of temperature inside a house," Energy Build., vol. 43, no. 2, pp. 748-758, 2011.

[98] S. Wu, J.-Q. Sun, "A physics-based linear parametric model of room temperature in office buildings," Build Environ., vol. 50, pp. 1-9, 2012. 
[99] Daniel L. Marino, Kasun Amarasinghe, Milos Manic, "Building Energy Load Forecasting using Deep Neural Networks," in Proceedings of the 42nd Annual Conference of the IEEE Industrial Electronics Society (IECON), 2016

[100] Abdul Aframand Farrokh Janabi-Sharifi, "Black-box modeling of residential HVAC system and comparison of graybox and black-box modeling methods," Energy and Buildings, vol. 94, pp. 121-149, 2015.

[101] K.W. Hipel, A.I. McLeod, "Time Series Modelling of Water Resources and Environmental Systems," Amsterdam, Elsevier, 1994.

[102] J. Ahn and S. Cho, “Anti-logic or common sense that can hinder machine's energy performance: Energy and comfort control models based on artificial intelligence responding to abnormal indoor environments," Applied Energy, vol. 204, pp. 117-130, Oct. 2017. 